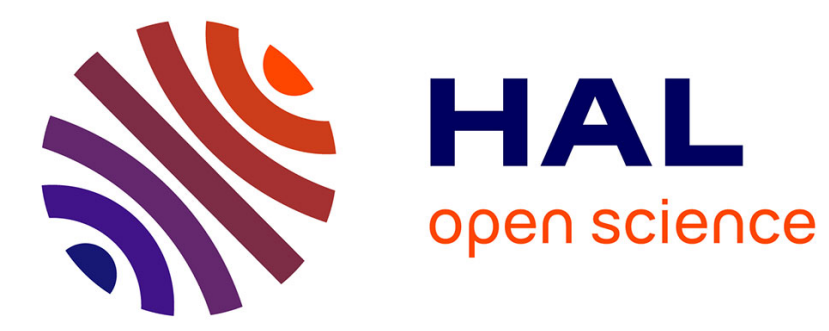

\title{
Plants may alter competition by modifying nutrient bioavailability in rhizosphere: a modeling approach
}

\author{
Xavier Raynaud, Benoit Jaillard, Paul W. Leadley
}

\section{To cite this version:}

Xavier Raynaud, Benoit Jaillard, Paul W. Leadley. Plants may alter competition by modifying nutrient bioavailability in rhizosphere: a modeling approach. The American Naturalist, 2008, 171 (1), pp.44-58. 10.1086/523951. bioemco-00167407

\section{HAL Id: bioemco-00167407 https://hal-bioemco.ccsd.cnrs.fr/bioemco-00167407}

Submitted on 10 Mar 2009

HAL is a multi-disciplinary open access archive for the deposit and dissemination of scientific research documents, whether they are published or not. The documents may come from teaching and research institutions in France or abroad, or from public or private research centers.
L'archive ouverte pluridisciplinaire HAL, est destinée au dépôt et à la diffusion de documents scientifiques de niveau recherche, publiés ou non, émanant des établissements d'enseignement et de recherche français ou étrangers, des laboratoires publics ou privés. 


\title{
Plants May Alter Competition by Modifying Nutrient Bioavailability in Rhizosphere: A Modeling Approach
}

\author{
Xavier Raynaud, ${ }^{1,2, *}$ Benoît Jaillard, ${ }^{3, \dagger}$ and Paul W. Leadley ${ }^{1, *}$
}

1. Laboratoire d'Ecologie, Systématique, et Evolution, Université Paris-Sud, Centre National de la Recherche Scientifique (CNRS) Unité Mixte de Recherche (UMR) 8079, F-91405, Orsay Cedex, France;

2. Université Pierre et Marie Curie-Paris 6, UMR (CNRS) 7618, Laboratoire Biogéochimie et Ecologie des Milieux Continentaux, 46 rue d'Ulm, F-75230 Paris Cedex 05, France;

3. Laboratoire de Biogéochimie du Sol et de la Rhizosphère, Institut National de la Recherche Agronomique, UMR 1222, Campus de la Gaillarde, 1 Place Pierre Viala, 34060 Montpellier Cedex 01, France

Submitted March 22, 2007; Accepted August 20, 2007; Electronically published November 15, 2007

ABSTRACT: Plants modify nutrient availability by releasing chemicals in the rhizosphere. This change in availability induced by roots (bioavailability) is known to improve nutrient uptake by individual plants releasing such compounds. Can this bioavailability alter plant competition for nutrients and under what conditions? To address these questions, we have developed a model of nutrient competition between plant species based on mechanistic descriptions of nutrient diffusion, plant exudation, and plant uptake. The model was parameterized using data of the effects of root citrate exudation on phosphorus availability. We performed a sensitivity analysis for key parameters to test the generality of these effects. Our simulations suggest the following. (1) Nutrient uptake depends on the number of roots when nutrients and exudates diffuse little, because individual roots are nearly independent in terms of nutrient supply. In this case, bioavailability profits only species with exudates. (2) Competition for nutrients depends on the spatial arrangement of roots when nutrients diffuse little but exudates diffuse widely. (3) Competition for nutrients depends on the nutrient uptake capacity of roots when nutrients and exudates diffuse widely. In this case, bioavailability profits all species. Mechanisms controlling competition for bio-

* Corresponding author; e-mail: xavier.raynaud@ens.fr.

† E-mail: benoit.jaillard@montpellier.inra.fr.

‡ E-mail: paul.leadley@u-psud.fr.

Am. Nat. 2008. Vol. 171, pp. 44-58. (c) 2007 by The University of Chicago. 0003-0147/2008/17101-42484\$15.00. All rights reserved.

DOI: $10.1086 / 523951$ available nutrients appear to be diverse and strongly depend on soil, nutrient, and plant properties.

Keywords: bioavailability, nutrient competition, diffusive supply, root soil occupation, nutrient uptake, rhizosphere.

In soil, plants can modify nutrient availability by releasing various chemicals from their roots, that is, root "exudates." Root exudates include a very broad spectrum of chemical compounds such as protons, organic anions, chelates, amino acids, sugars, and enzymes. These exudates modify nutrient availability through various mechanisms such as ion exchange, chemical desorption or complexation, mineral dissolution or weathering, organic mineralization, and acceleration of the turnover rate of the soil microbial loop (Marschner 1995; Hinsinger et al. 2001; Dakora and Phillips 2002; Bonkowski 2004). The importance of root exudates in determining the nutrient bioavailability — that is, the availability induced by biological activity-has been widely highlighted and discussed at the level of individual plants or whole ecosystems (e.g., Clarholm 1985a, 1985b, 1989; Ingham et al. 1986a, 1986b; Kirk and Saleque 1995; Kirk et al. 1999a, 1999b; Paterson 2003; Bonkowski 2004). However, the consequences of plant exudation on competition for soil nutrients have rarely been explored. Indeed, depending on the extent to which these exudates diffuse around roots, changes in nutrient availability may affect nutrient uptake at a very local scale, that is, in the rhizosphere, or at the scale of plant individuals and their neighbors. In the latter case, exuding plant species may behave as ecosystem engineers sensu Jones et al. (1994), because they increase the nutrient uptake of other plants growing in their vicinity. Such a mechanism may therefore have considerable effect in controlling the competition for soil resources and the dynamics of plant communities.

A wide variety of models have been developed to study competition for soil nutrients between plants (e.g., Tilman 1988; Berendse and Elberse 1990; Huston and DeAngelis 1994; Tilman et al. 1997; Loreau 1998). However, none of these models explicitly take into account the effects of plant exudates on nutrient availability. Using a model of plant 
competition for nutrients at the scale of individual roots in a small patch of soil, Raynaud and Leadley (2004) found that the partitioning of a given nutrient between two competing species depended on the constraints on the nutrient diffusion through the soil. Nutrient partitioning ranged between a value solely determined by root distribution in the soil and a value determined by nutrient uptake capacities of the roots. Such models are useful for understanding the mechanisms controlling nutrient competition, such as nutrient uptake capacity of roots, soil exploration by roots, and so on (Smethurst and Comerford 1993; Raynaud and Leadley 2004; Craine et al. 2005). Accounting for root effects on nutrient bioavailability could substantially alter our view on the relative importance of these mechanisms and their effects on the functioning of the terrestrial ecosystems.

The aim of this article is to evaluate the importance of nutrient bioavailability on plant competition for soil nutrients using a mechanistic model of nutrient diffusion in the soil and uptake by roots. More precisely, the goal is to study the importance of nutrient and exudate mobility in soil on the competition for nutrients between plant species. For example, in cases where solutes can diffuse greatly in the soil, all species might benefit from increased bioavailability. In contrast, in cases where soil diffusion properties limit solute movements, increased bioavailability should be limited to the soil in the immediate vicinity of exuding roots. In this last case, the partitioning of nutrients between species might depend on root system properties. The model is based on the PARIS model developed by Raynaud and Leadley (2004), which has previously been used to illustrate the importance of soil water content in the partitioning of nutrients between competing plants in the absence of exudates. In the first step, the model was parameterized using experimental data to simulate the effects of citrate exudation on phosphate uptake. In particular, organic anions such as citrate that are exuded by roots may mobilize other anions such as phosphate that are strongly adsorbed on mineral phases and thus increase their availability in soil (Marschner 1995; Jones 1998). Kirk et al. $(1999 a, 1999 b)$ have calculated that citrate exudation by rice roots and the subsequent mobilization of phosphate in an acid soil leads to a more than $100 \%$ increase in $\mathrm{P}$ uptake by plants. In this example, our objective is to examine how differences in citrate exudation between plant species can affect phosphate uptake between competing plants in soils where citrate exudation occurs. Other works have demonstrated the role of roots in decreasing soil $\mathrm{pH}$ and consequently increasing the bioavailability and uptake by plants of some metal ions such as zinc or aluminium (Loosemore et al. 2004; Calba et al. 2004).

We have also examined the generality of our results by exploring the sensitivity of the model as parameterized for citrate and phosphorus to a wide range of values of key parameters, in particular those parameters characterizing the behavior of exudates that increase nutrient bioavailability and root distributions. We have looked at several aspects of the consequences of nutrient bioavailability on competition, such as the development of the rhizosphere, as well as the consequences of exudates on plant competition when both species increase nutrient availability and when only one species does so. Consequences of this phenomenon at the ecosystem scale are also discussed.

\section{Model Development}

The model we have used for this study (called PARIS-B for "plant and their roots interactions in the soil, biological interactions version") is based on a previously published model (called PARIS-M for "plant and their roots interactions in the soil, mechanistic version"; Raynaud and Leadley 2004). The structure and main predictions of the PARIS$\mathrm{M}$ model are summarized in the following paragraph.

\section{The PARIS-M Model}

The PARIS-M model uses well-known mechanistic nutrient diffusion and absorption relationships to simulate nutrient concentrations and nutrient uptake by plants at the scale of individual roots in a small patch of soil (Raynaud and Leadley 2004). Outputs from the PARIS-M model are maps of nutrient concentration and estimations of total and rates of nutrient uptake for all species in competition. In the model, nutrients move through a grid of identical soil elements (hereafter referred to as voxels) by diffusion, as modeled by Fick's first law, and are taken up by roots, as described by a Michaelis-Menten equation (see app. A). The grid structure makes it possible to simulate the uptake of several species with contrasting distributions or uptake capacities of roots. The voxel size is determined by the size of the smallest root in the map.

The model PARIS-M relies on the following parameters. The diffusive supply $b D_{\mathrm{e}}$ of a nutrient is the product between the buffer power $b$ of soil for the nutrient and its effective diffusion $D_{\mathrm{e}}$ in soil. It is defined by the equation (van Rees et al. 1990)

$$
b D_{\mathrm{e}}=D_{1} \theta f_{1}
$$

where $D_{1}$ is the diffusion coefficient of the nutrient in water, $\theta$ is the volumetric water content of soil, and $f_{1}$ is the tortuosity factor of soil ( $f_{1}$ varies with and is of the same order of magnitude as $\theta$; Tinker and Nye 2000). The parameter $D_{1}$ ranges between $0.5 \times 10^{-5}$ and $2 \times 10^{-5} \mathrm{~cm}^{2}$ $\mathrm{s}^{-1}$ for most macronutrients (Vanysek 2000), whereas $\theta$ ranges between 0.15 and $0.65 \mathrm{~cm}^{3} \mathrm{~cm}^{-3}$. Therefore, the 
diffusive supply $b D_{\mathrm{e}}$ depends primarily on the soil water content $\theta$ (see app. A), and its values range from $10^{-7}$ to $10^{-5} \mathrm{~cm}^{2} \mathrm{~s}^{-1}$ for most macronutrients (see Raynaud and Leadley 2004). In the PARIS-M model, nutrient availability $(S)$ is constant in space and time. The model does not take into account nutrient movements in the water mass flow, but it has been shown that the rate of water influx at the root surface plays only a minor role in nutrient uptake of single species under most conditions (Williams and Yanai 1996; Leadley et al. 1997) and was negligible in a model of interspecific competition between pine and grasses (Smethurst and Comerford 1993). Exceptions to this are combinations of very high water flux into roots and low diffusive supply. We do not know, however, how differences in water uptake between species might affect nutrient flux in a spatially explicit model of plant competition, so PARIS-M is most appropriately used in conditions where the water uptake rates per unit of root are similar for all species.

In a given soil volume, a plant species $i$ can be characterized by two macroscopic parameters: its sink strength $\gamma_{i}$ and the soil volume $\sigma_{i}$ that its roots occupy. The sink strength of a species is the maximum nutrient uptake capacity of all the roots of this species within a given soil volume. It is equal to the product of the total surface area of the roots in the soil patch and the uptake capacity $I_{\max _{i}}$ per unit root area of the species:

$$
\gamma_{i}=\left(2 \pi r_{i} N_{i}\right) I_{\max _{i}},
$$

where $r_{i}$ is the radius and $N_{i}$ the number of roots of the species. The soil volume $\sigma_{i}$ occupied by a species' roots is an index derived from Thiessen tessellations (also know as Dirichlet or Voronoi tessellations). The Thiessen polygon surrounding a root corresponds to the polygon formed by the bisectors of the lines joining the root with all its neighbors. It is a measure of the volume of soil that would be exploited by this root, given that all other roots in the map are identical in terms of uptake capacity (Raynaud and Leadley 2004).

Most of the analysis of the PARIS-M model was done at equilibrium, that is, when the sum of the uptake rates of all roots is equal to the total nutrient supply in the given soil volume. At equilibrium, nutrient gradients around roots do not change with time anymore. The analysis of the PARIS-M model showed that (1) equilibrium between uptake of nutrient by plants and nutrient supply occurs whenever nutrient supply is lower than the total maximum nutrient uptake capacities of all species in the soil volume considered, (2) equilibrium occurs within a few days for a broad range of diffusive supplies, and (3) nutrient uptake by roots in competition at equilibrium $\left(U_{i}^{*}\right.$; quantity of nutrient taken by all roots of a species per unit time) follows a sigmoid curve when plotted against the diffusive supply of the nutrient on a log scale (Raynaud and Leadley 2004). The uptake rate of a species in competition ranged between its relative occupation ratio (i.e., the soil volume occupied by the roots of the species relative to the whole soil volume, $\sigma_{i} / \sum \sigma_{j}$ ) at low diffusive supply and its relative sink strength ratio (i.e., the uptake capacity of all the roots of the species relative to the uptake capacities of all roots in the soil patch, $\gamma_{i} / \sum \gamma_{j}$ ) at high diffusive supply. In the case of two competing species, nutrient partitioning between species can also be estimated by calculating the uptake rate ratio $U_{2}^{*} / U_{1}^{*}$, that is, the ratio of nutrient uptake rates of the species at equilibrium. When this ratio is equal to 1 , both species have taken up the same quantity of nutrient, whereas when the ratio is different from 1 , one of the species has taken up more nutrient than the other. The fact that a species can take up more nutrient than the other can be due to the fact that a species has a higher number of roots but also, in the case of two species with identical root densities, to differences in sink strength or soil occupation by roots. In their analysis of the PARISM model, Raynaud and Leadley (2004) found that the uptake rate ratio also followed a sigmoid-shaped curve when plotted against the log of the diffusive supply of the nutrient, ranging between the occupation ratio $\sigma_{2} / \sigma_{1}$ and the sink strength ratio $\gamma_{2} / \gamma_{1}$.

\section{Development of the PARIS-B Model}

The PARIS-B model is a modification of the PARIS-M model that makes it possible to simulate changes in nutrient availability due to root activity, that is, the nutrient bioavailability. We suppose that the roots of plant species $i$ release a chemical factor $C$ at a rate $E_{c}\left(\mathrm{mmol} \mathrm{cm}_{\text {root }}{ }^{-2}\right.$ $\mathrm{s}^{-1}$ ). The chemical factor diffuses through the soil on the basis of Fick's law and, therefore, depends on the diffusion parameters $b_{C}$ and $D_{\mathrm{e} C}$. However, the chemical factor disappears in the soil at a rate $\mu_{C}\left(\mathrm{~s}^{-1}\right)$ in order to simulate its biological or chemical transformation into an inactive form. While it is active, the chemical factor changes the nutrient availability on the basis of the following relationship:

$$
S_{\nu}=S_{\min }+\left(S_{\max }-S_{\min }\right) \frac{C_{\nu}}{K_{C}+C_{\nu}}
$$

where $\left.C_{\nu}(\mathrm{mmol} \mathrm{cm})^{-3}\right)$ is the concentration of chemical factor $C$ in voxel $\nu, K_{C}\left(\mathrm{mmol} \mathrm{cm}{ }^{-3}\right)$ is the half-saturation coefficient of the bioavailability function, and $S_{\min }, S_{\max }$, and $S_{\nu}\left(\mathrm{mmol} \mathrm{cm}^{-3} \mathrm{~s}^{-1}\right)$ are, respectively, the availability without the chemical factor (i.e., the soil basal availability, which is constant in space and time), the maximum availability when the soil is saturated by the chemical factor 
(i.e., the potential bioavailability, which is constant in space and time), and the actual nutrient bioavailability in soil voxel $\nu$.

The movements of both nutrient and chemical factor depend on the soil water content $\theta$. Consequently, the model PARIS-B was modified to explicitly take into account the water content of soil. In order to simulate simultaneous changes in nutrient and chemical factor diffusion for different soil water content values, diffusive supplies $b D_{\mathrm{e}}$ and $b_{C} D_{\mathrm{e} C}$ are calculated using equation (1), where $D_{1}, D_{1 C}$ and $\theta$ are given as parameters. Because both nutrient and exudate diffusive supply are calculated using equation (1), they co-vary with $\theta$ and are proportional to $D_{1} / D_{1 C}$. The tortuosity factor $f_{1}$ is modeled following Olesen et al. (2001) as

$$
f_{1}=1.1\left(\theta-\theta_{\mathrm{th}}\right)
$$

where $\theta_{\text {th }}\left(\mathrm{cm}^{3} \mathrm{~cm}^{-3}\right)$ is the threshold water content, that is, the value for which diffusion ceases because of discontinuous diffusive pathways (Olesen et al. 2001). Soil buffer powers $b$ and $b_{C}$ are calculated following van Rees et al. (1990):

$$
b=\theta+\rho K_{d}
$$

where $\rho$ is the soil density $\left(\mathrm{g} \mathrm{cm}^{-3}\right)$ and $K_{d}\left(\mathrm{~cm}^{3} \mathrm{~g}^{-1}\right)$ is the ratio between the concentration of nutrient adsorbed on the soil solid phase and the concentration in the soil solution. Parameters of the PARIS-B model (including the parameters in common with PARIS-M) used in this analysis are presented in table 1.

\section{Model Parametrization and Analysis}

We have studied in detail the behavior of the model using three root maps where roots were distributed in space on the basis of a random (Poisson) distribution. One map contained two species having 20 roots per species; the estimated occupation ratio $\sigma_{2} / \sigma_{1}$ calculated using the PARIS-M model was 0.82 (species 2 occupies a smaller volume than species 1 ). The second map contained two species having 10 roots per species; the occupation ratio $\sigma_{2} / \sigma_{1}$ was 1.15 (species 2 occupies a larger volume than species 1). The third map contained two species having five roots per species: the occupation ratio $\sigma_{2} / \sigma_{1}$ was 0.90 (species 2 occupies a smaller volume than species 1). All maps are $1 \mathrm{~cm}^{2}$ (for a discussion of the extrapolation to larger spatial scales, see Raynaud and Leadley 2004). These root maps correspond to root densities measured for temperate grasslands (Raynaud and Leadley 2004), with a total of 40 roots $\mathrm{cm}^{-2}$ at the high end and 10 roots $\mathrm{cm}^{-2}$ at the low end of observed root densities.
To illustrate the relative effects of uptake kinetics on competition, we have set $I_{\max _{2}}=2 I_{\max _{1}}$; that is, species 2 has a maximum uptake rate double that of species 1 . Our previous work with PARIS-M suggested that the behavior of the model under differences in uptake rates could be extrapolated to a wide range of realistic maximum uptake rates.

The PARIS-B model was parameterized following values given in table 1 . We have chosen parameters that are representative of low to moderate fertility grasslands with a sandy, acidic soil (for details, see Raynaud and Leadley 2004).

In the first step, we have parameterized the model to simulate phosphate mobilization by citrate. Values of the $C$ exudation rate $\left(E_{C}\right)$ were chosen in the range of exudation rates for organic anions found in the literature $\left(10^{-8}\right.$ mmol cm ${ }^{-2} \mathrm{~s}^{-1}$; Nielsen et al. 1994; Jones and Darrah 1995; Kirk et al. 1999a, 1999b). Kirk et al. (1999a) measured a decay rate $\mu_{C}$ of $4.16 \times 10^{-5} \mathrm{mmol} \mathrm{s}^{-1}$ for citrate in soil. Given the uncertainty in the decay rate, we have done a wide-ranging sensitivity analysis to gain broad insight into how root exudates might alter plant competition. We have therefore examined the sensitivity of plant phosphorus uptake to citrate decay rate using decay rate values of $10^{-5}$, the measured rate of $4.16 \times 10^{-5}$ and $10^{-3} \mathrm{mmol} \mathrm{s}^{-1}$ (we also show some results for the extremely rapid decay rate of $10^{-2} \mathrm{mmol} \mathrm{s}^{-1}$ ). The corresponding half-lives of $C$ are, respectively, $20 \mathrm{~h}, 4.6 \mathrm{~h}$, and $10 \mathrm{~min}$. In this range, a low decay rate would be more representative of an exudate that disappears slowly through biological processes (as phytosiderophore or organic anions), whereas a high decay rate would correspond to an exudate that reacts chemically within the soil to make the nutrient bioavailable (as protons). We studied the sensitivity of the model for this parameter because changes in decay rate should alter the extent to which exudates move in the soil.

In all simulations, we considered that the chemical factor $C$ exuded by roots increased the bioavailability of the studied nutrient. To better understand the implications of root-induced changes in nutrient availability, we first studied its consequences for nutrient partitioning between two competing species, considering that both species exuded the chemical factor at the same rate $E_{C}$ and analyzed the sensitivity of the results depending on the decay rate $\mu_{C}$ of $C$. In the second step and in order to generalize our results, we have done a less wide-ranging sensitivity analysis of the model using 12 root maps (i.e., the three maps used for the intensive analysis above and nine new maps) for which root number per species was randomly chosen between 1 and 20 and root distribution in space followed a random (Poisson) distribution. Root map and species characteristics are given in appendix B. For this sensitivity analysis, we ran simulations in order to calculate the up- 
Table 1: Description of the symbols for the parameters and variables used in the PARIS-B model

\begin{tabular}{|c|c|c|c|}
\hline Parameter & Description & Used range & Units \\
\hline \multicolumn{4}{|l|}{ Soil: } \\
\hline$\nu$ & Voxel index & & Unitless \\
\hline$z$ & Thickness of soil & 1 & $\mathrm{~cm}$ \\
\hline$\rho$ & Soil density & 1.16 & $\mathrm{~g} \mathrm{~cm}^{-3}$ \\
\hline$\theta$ & Soil water content & $.15-.65$ & $\mathrm{~cm}^{3} \mathrm{~cm}^{-3}$ \\
\hline$\theta_{f}$ & Soil water content threshold & .1 & $\mathrm{~cm}^{3} \mathrm{~cm}^{-3}$ \\
\hline \multicolumn{4}{|l|}{ Plant: } \\
\hline$i$ & Species index & & Unitless \\
\hline$r_{i}$ & Root radius & .1 & $\mathrm{~mm}$ \\
\hline$N_{i}$ & Number of roots of species $i$ in the map $\left(1 \mathrm{~cm}^{2}\right)$ & $5-20$ & Unitless \\
\hline$\sigma_{i}$ & Volume of soil occupied by species $i$ in the map & $.30-1.34$ & $\mathrm{~cm}^{3}$ \\
\hline$I_{\max i}$ & $\begin{array}{l}\text { Maximum root uptake rate per unit of root surface area for } \\
\text { species } i\end{array}$ & $5 \times 10^{-9}-2 \times 10^{-8}$ & $\mathrm{mmol} \mathrm{cm} \mathrm{c}^{-2} \mathrm{~s}^{-1}$ \\
\hline$K_{M i}$ & $\begin{array}{l}\text { Half-saturation constant for nutrient uptake kinetics of } \\
\text { species } i\end{array}$ & $10^{-4}$ & $\mathrm{mmol} \mathrm{cm}{ }^{-3}$ \\
\hline$I_{r, i}$ & Uptake rate for a root element $r$ of species $i$ & & $\mathrm{mmol} \mathrm{s}^{-1}$ \\
\hline$\gamma_{i}$ & Sink strength of species $i$ & $.25-4$ & $\mathrm{mmol} \mathrm{s}^{-1}$ \\
\hline$U_{i}$ & Nutrient uptake rate for species $i^{\mathrm{a}}$ & & $\mathrm{mmol} \mathrm{s}^{-1}$ \\
\hline$E_{C, i}$ & Exudation rate of the chemical factor $C$ for species $i$ & $10^{-8}$ & $\mathrm{mmol} \mathrm{cm} \mathrm{cs}^{-2}$ \\
\hline \multicolumn{4}{|c|}{ - } \\
\hline$P_{\nu}$ & Nutrient soil solution concentration in voxel $\nu$ & & $\mathrm{mmol} \mathrm{cm} \mathrm{cm}^{-3}$ \\
\hline$P_{\text {init }}$ & Initial nutrient concentration in the soil solution & $1.2 \times 10^{-5}$ & $\mathrm{mmol} \mathrm{cm} \mathrm{cm}^{-3}$ \\
\hline$K_{d P}$ & Distribution coefficient of nutrient & 86.2 & $\mathrm{~cm}^{3} \mathrm{~g}^{-1}$ \\
\hline$D_{1}$ & Diffusion coefficient of the nutrient in water & $.82 \times 10^{-5}$ & $\mathrm{~cm}^{2} \mathrm{~s}^{-1}$ \\
\hline$D_{\mathrm{e}}$ & Effective diffusion coefficient of nutrient in the soil & & $\mathrm{cm}^{2} \mathrm{~s}^{-1}$ \\
\hline$b$ & Soil buffer capacity for nutrient & & Unitless \\
\hline$S_{\min }$ & Soil nutrient availability without chemical factor $C$ & $10^{-12}$ & $\mathrm{mmol} \mathrm{cm} \mathrm{c}^{-3} \mathrm{~s}^{-1}$ \\
\hline \multicolumn{4}{|c|}{ Chemical factor: } \\
\hline$C_{\nu}$ & Chemical factor soil solution concentration in voxel $\nu$ & & $\mathrm{mmol} \mathrm{cm} \mathrm{cm}^{-3}$ \\
\hline$K_{d C}$ & Distribution coefficient of the chemical factor & 4.4 & $\mathrm{~cm}^{3} \mathrm{~g}^{-1}$ \\
\hline$D_{\mathrm{lC}}$ & Diffusion of chemical factor $C$ in water & $.62 \times 10^{-5}$ & $\mathrm{~cm}^{2} \mathrm{~s}^{-1}$ \\
\hline$D_{\mathrm{e} C}$ & Effective diffusion of chemical factor $C$ in soil & & $\mathrm{cm}^{2} \mathrm{~s}^{-1}$ \\
\hline$b_{C}$ & Soil buffer capacity for the chemical factor $C$ & & Unitless \\
\hline$S_{\max }$ & $\begin{array}{l}\text { Maximum bioavailability of soil, i.e., when the soil is } \\
\text { saturated by the chemical factor } C\end{array}$ & $5 \times 10^{-10}$ & $\begin{array}{l}\left.(\mathrm{mmol} \mathrm{cm})^{-3}\right) \\
\left.\quad(\mathrm{mmol} \mathrm{cm})^{-3}\right)^{-1} \mathrm{~s}^{-1}\end{array}$ \\
\hline$S_{\text {tot }}$ & Total nutrient supply in the simulated map & & $\mathrm{mmol} \mathrm{s}^{-1}$ \\
\hline$S_{\nu}$ & $\begin{array}{l}\text { Actual nutrient bioavailability in soil, i.e., the bioavailability } \\
\text { induced by the chemical factor } C \text { in voxel } \nu\end{array}$ & & $\mathrm{mmol} \mathrm{cm}{ }^{-3}$ \\
\hline$K_{C}$ & Half-saturation function of the bioavailability factor & $10^{-5}$ & $\mathrm{mmol} \mathrm{cm} \mathrm{cm}^{-3}$ \\
\hline$\mu_{C}$ & Decay rate of the chemical factor $C$ & $10^{-5}-10^{-3}$ & $\mathrm{mmol} \mathrm{s}^{-1}$ \\
\hline
\end{tabular}

Note: The range of values explored in the various sensitivity analyses are given for each parameter. A single value for a parameter indicates that no sensitivity analysis was done for this parameter. Some parameters are used in the equations given in appendix A.

${ }^{a}$ An asterisk indicates value at equilibrium.

take rate ratio between species for two extreme values of soil water availability (0.11 and 1.0$)$ and two decay rates $\left(10^{-5}\right.$ and $\left.10^{-3} \mathrm{~s}^{-1}\right)$ and compared them with particular parameter ratios $\left(N_{2} / N_{1}, \gamma_{2} / \gamma_{1}\right.$, and $\left.\sigma_{2} / \sigma_{1}\right)$. The two values of soil water availability, although extreme, were chosen as an illustration because they lead to highly contrasting values of diffusive supply for nutrient and exudates $\left(9.92 \times 10^{-9}\right.$ and $8.11 \times 10^{-6} \mathrm{~cm}^{2} \mathrm{~s}^{-1}$, respectively, for phosphate).
We then studied the partitioning of nutrient between these two species in the case where only one species was able to modify nutrient availability. In this last case, our objective was to see whether a species that is unable to change nutrient availability can use nutrients made bioavailable by another species. For this analysis, we used only one map $\left(\sigma_{2} / \sigma_{1}=0.82\right)$.

In order to obtain a better understanding of the consequences of the exudation of the chemical factor on com- 
petition, we have chosen to analyze the model outputs in a way similar to Raynaud and Leadley's (2004) analysis of the PARIS-M model. Our analysis is based on the behavior of the model at equilibrium. Although, in some cases, the equilibrium between uptake and supply can occur after several months (very dry soils, i.e., very low diffusive supplies), equilibrium generally occurs in a few days in most of the range of soil water content used in this analysis (data not shown). We also have estimated the role of bioavailability changes on nutrient partitioning between species by plotting the nutrient uptake rate ratio of two species $\left(U_{2}^{*} / U_{1}^{*}\right)$ at equilibrium as a function of nutrient diffusive supply under different bioavailability scenarios.

\section{Results}

Influence of Root Density, Soil Water Content, and Decay Rate on the Spatial Extent of the Chemical Factor

Figure 1 shows the distribution of the nutrient supply (i.e., bioavailability) for two plant species exuding a chemical factor, over a broad range of decay rates of the chemical factor $\left(\mu_{C}\right)$ and soil water content $(\theta)$ at two root densities. In this set of simulations, the roots of the two plant species exude the same chemical factor $C$, which is degraded at the same decay rate decay $\mu_{C}$. In figure $1 a$, both species have 20 roots per species, and in figure $1 b$, both species have five roots per species. Comparing all 12 plots shows that these three parameters - soil water content, decay rate, and root density-have a major influence on the distribution of the nutrient supply in the map. We will consider separately the influence of the three parameters in order to untangle their respective roles in controlling the heterogeneity of nutrient bioavailability.

Role of Root Density $\left(\mathrm{n}_{\mathrm{i}}\right)$. Comparing figures $1 a$ and $1 b$ shows that, although the chemical factor behaves similarly at both densities, nutrient bioavailability is more localized around the roots at low density than at high density. Indeed, because low densities mean greater distance between two neighboring roots, our simulations at low root density show more localized nutrient bioavailability simply because the chemical factor has more distance to go in order to diffuse throughout the whole map.

Role of Decay Rate $\left(\mu_{\mathrm{C}}\right)$. When the decay rate is low, equal to $10^{-5} \mathrm{~s}^{-1}$, the chemical factor spreads across most of the soil map, regardless of the root density. In this case, nutrient supply is near its maximum $\left(S_{\max }=5.6 \times 10^{-10}\right.$ mmol cm $\left.\mathrm{cm}^{-3} \mathrm{~s}^{-1}\right)$ throughout the map. In contrast, when decay rate is high, equal to $10^{-3} \mathrm{~s}^{-1}$, the chemical factor is quickly inactivated and thus cannot spread throughout the map. In this case, the bioinfluenced soil volume (i.e., the volume of soil with high concentration of the chemical factor and high nutrient supply) is concentrated in the close vicinity of roots, making small bioavailability "hotspots." Therefore, the higher the decay rate of the chemical factor, the less it spreads away from the roots, which consequently decreases total nutrient bioavailability in the map.

Role of Soil Water Content ( $\theta)$. Soil water content strongly modifies the diffusive supply of the chemical factor (eq. [1]). As a consequence, changes in soil water content modify the extent to which the chemical factor diffuses around the root and thus alter the sizes of the bioavailability hotspots around roots.

Role of Soil Basal Nutrient Availability $\left(\mathrm{S}_{\text {min }}\right)$. We also explored the importance of the nutrient minimum supply rate (data not shown). Whenever $S_{\min }$ is kept low compared with $S_{\max }$, this parameter does not change the distribution of bioavailability "hotspots" in the map but only slightly increases nutrient supply in zones where the availability factor cannot spread to, therefore slightly increasing the overall bioavailability in the map. When $S_{\min }$ is high compared with $S_{\max }$, then the relative contribution of bioavailability is low and the trivial result is that the system behavior approaches that described by Raynaud and Leadley (2004).

At both rooting densities, the broadest extension of nutrient supply is simulated for high soil water content and low decay rate, whereas the most restrained extension is simulated for lower soil water content and the fastest decay rate. Total bioavailability in the map is slightly higher at high root density than at low root density because there are more roots and thus more chemical factor emitted in the soil.

\section{Consequences of Nutrient Supply Localization on Nutrient Partitioning between Two Plants Having Exudates}

Nutrient concentrations in the soil show depletion zones around roots (data not shown), which are typical of measured nutrient concentration profiles (Tinker and Nye 2000). Average nutrient concentrations decrease with soil water content $\theta$ and with decay rate $\mu_{C}$ of the chemical factor (data not shown) because of a decrease in the total nutrient supply across the map. This decrease in nutrient supply is due to (1) for a given decay rate, the dilution of the chemical factor with increasing soil water content and (2) for a given soil water content, the quicker disappearance of the chemical factor with increasing decay rate.

Figure 2 shows, for two different root maps, the change in the uptake rate ratio at equilibrium as a function of the 

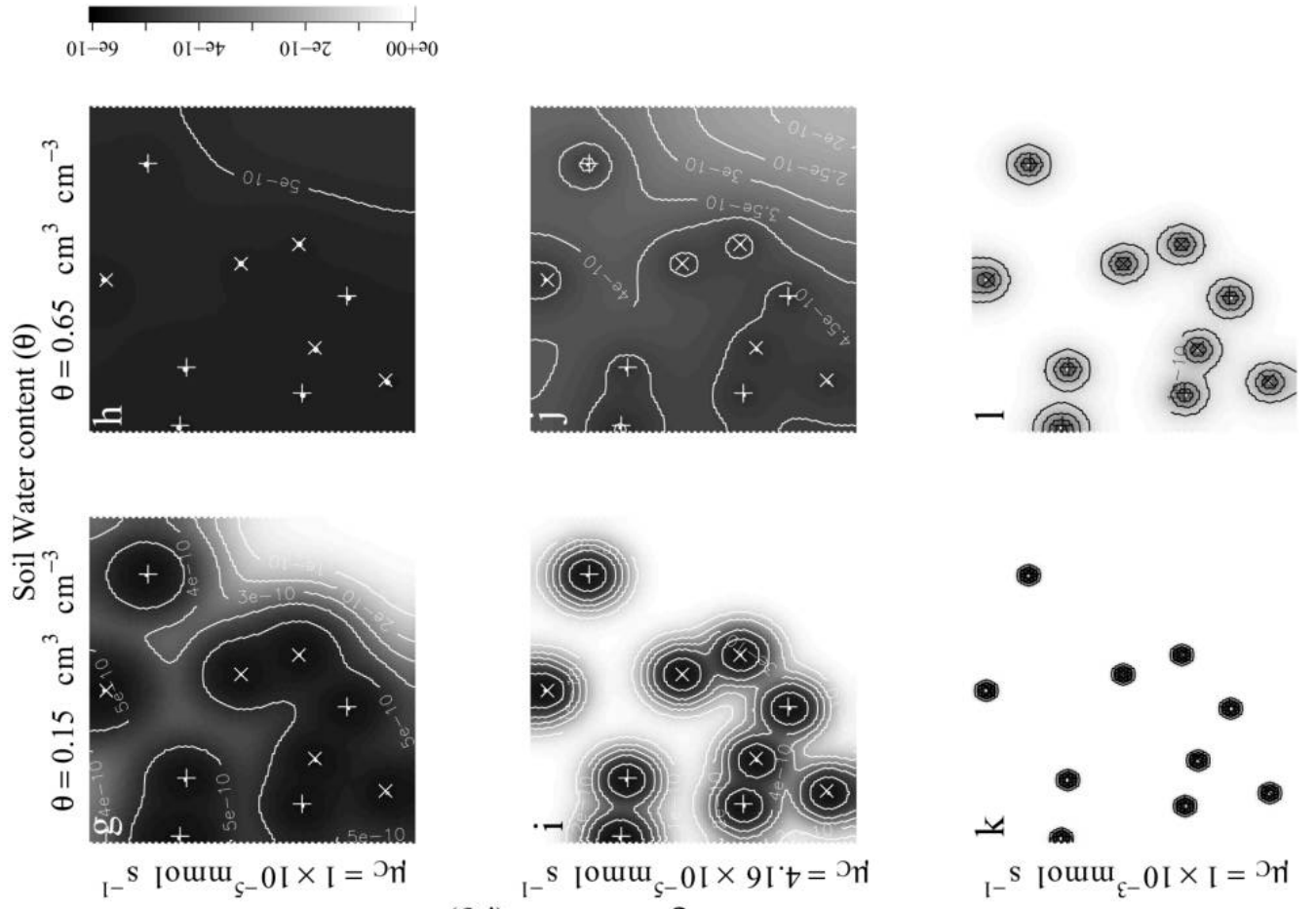

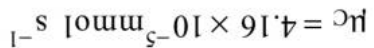

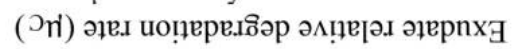
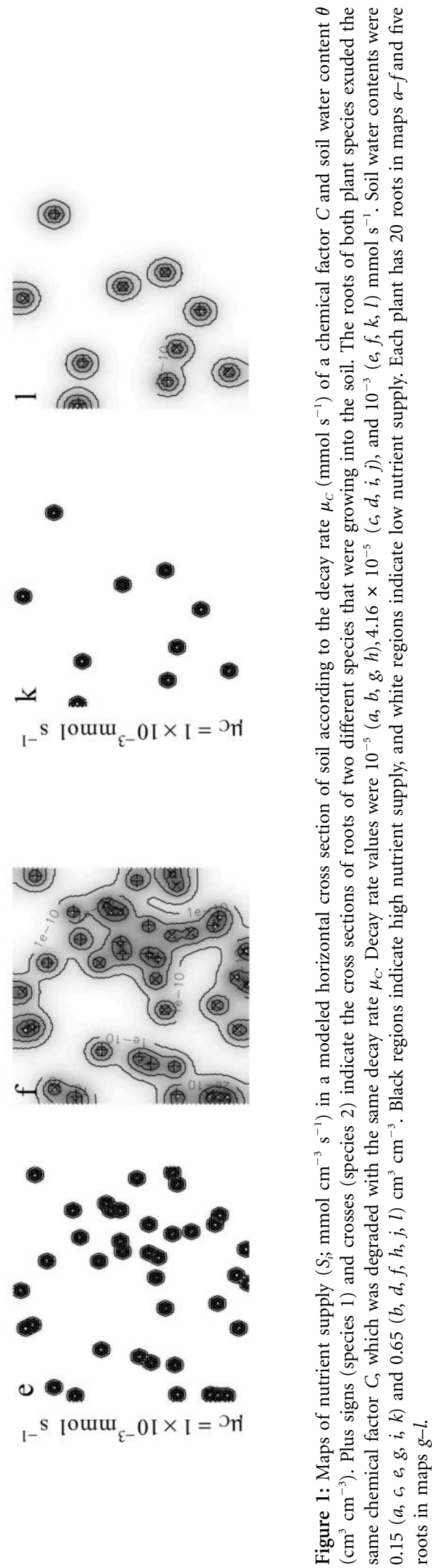

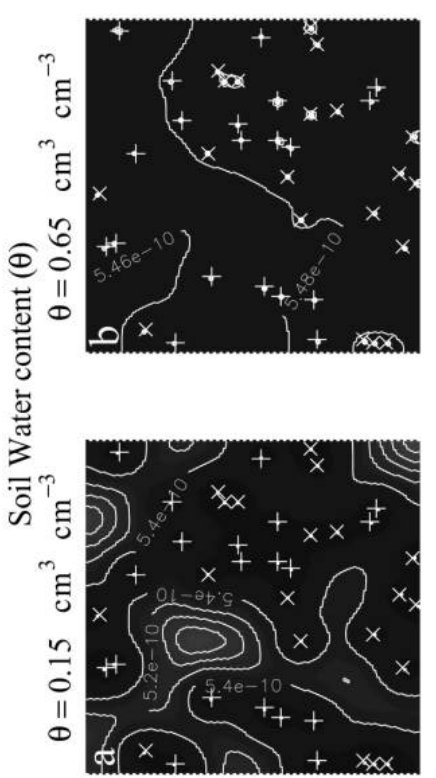

${ }_{\text {I- }}$ S $_{\text {[Oumu }}{ }_{\text {S- }} 0 \mathrm{I} \times \mathrm{I}=\mathrm{PNI}^{\mathrm{N}}$
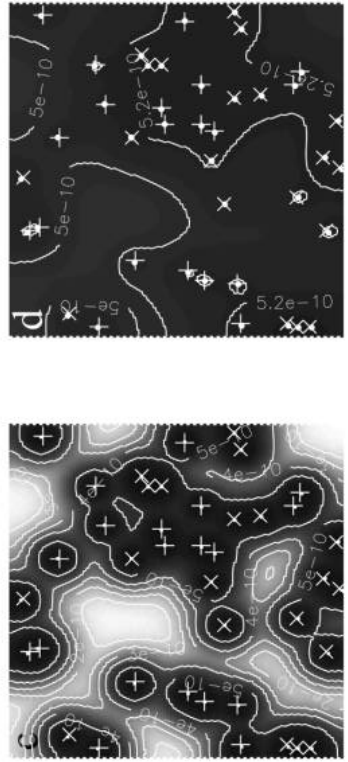

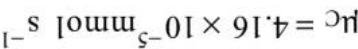

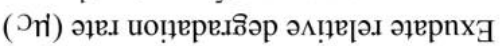
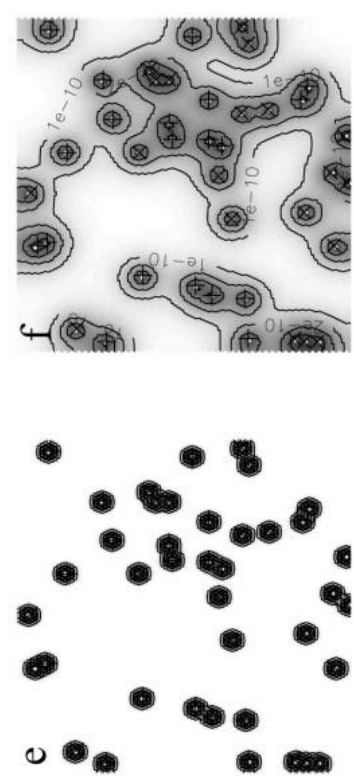

$\mathrm{I}_{-} \mathrm{S}_{\text {Ioumu }} \mathrm{\varepsilon}_{-} 0 \mathrm{I} \times \mathrm{I}=\mathrm{OH}$ 

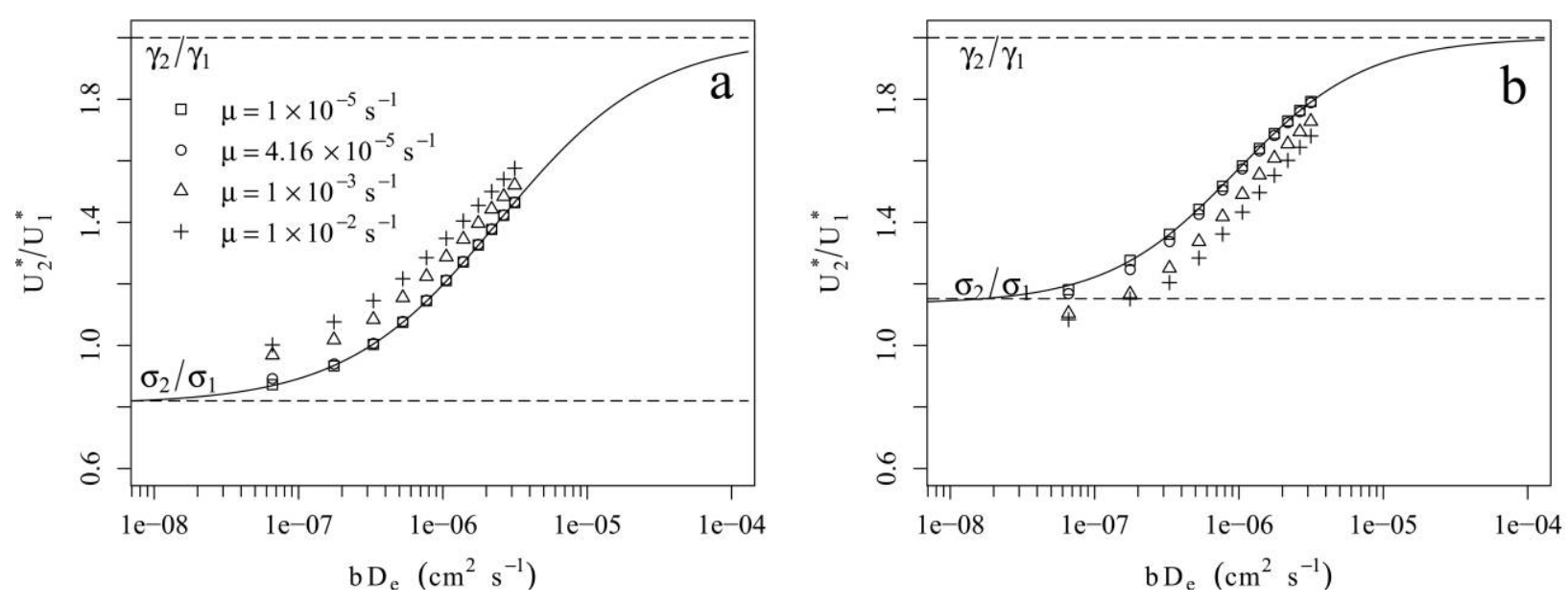

Figure 2: Changes in the uptake rate ratio at equilibrium $U_{2}^{*} / U_{1}^{*}$ as a function of the diffusive supply $b D_{\mathrm{e}}$ when the roots of both plant species exuded the same chemical factor $C$. The soil occupation ratio $\sigma_{2} / \sigma_{1}$ of roots of two species in the map was $\sigma_{2} / \sigma_{1}=0.82(a)$ and $\sigma_{2} / \sigma_{1}=1.15(b)$. The bottom horizontal dashed line corresponds to the value of soil occupation ratio $\sigma_{2} / \sigma_{1}$. The top horizontal line corresponds to the value of sink strength ratio $\gamma_{2} / \gamma_{1}$. The chemical factor $C$ exuded by roots was degraded with the decay rate $\mu_{C}$. The decay rate values were $10^{-5}$ (squares), $4.16 \times 10^{-5}$ (circles), $10^{-3}$ (triangles), and $10^{-2}$ (plus signs) $\mathrm{mmol} \mathrm{s}^{-1}$. The sigmoid curve corresponds to the calculated uptake rate ratio under constant nutrient supply. $b_{\mathrm{C}} D_{\mathrm{eC}}$ co-vary with $b D_{\mathrm{e}}$ by a factor $D_{\mathrm{IC}} / D_{1}=0.756$.

diffusive supply of the nutrient for different values of the decay rate $\mu_{C}$ of the chemical factor. By comparison with the results of the PARIS-M model (i.e., without exudates), the uptake rate ratio was modified at low diffusive supply $b D_{\mathrm{e}}$ for high values of the decay rate $\mu_{C}$ of chemical factor. This change also depended on the initial value of the soil occupation ratio $\sigma_{2} / \sigma_{1}$ compared with $N_{2} / N_{1}$. In figure $2 a$, the uptake rate ratio increases at low diffusive supply from $\sim 0.8$ (the map's $\sigma_{2} / \sigma_{1}$ ) to $N_{2} / N_{1}$ (which is equal to 1 in this map) for increasing values of the decay rate. In contrast, in figure $2 b$, the uptake rate ratio decreases from $\sim 1.1$ (the map's $\sigma_{2} / \sigma_{1}$ ) to $N_{2} / N_{1}$ (also equal to 1 for this map) for increasing values of the decay rate. In both cases, the uptake rate ratio tends toward the ratio of root numbers, which is $1: 1$ in both maps. The other statistical parameters do not change much (table B1). This occurs because each root creates its own highly localized zone of nutrient bioavailability where nutrient is taken up primarily by that root. In this case, the amount of nutrients taken up by the plants is proportional to the number of roots, regardless of the number of roots of the competing species (at least at root densities that are realistic for grasslands).

The aim of the sensitivity analysis was to generalize these results over a broader range of root distributions in the case where diffusion rates are either high (wet soils) or very low (dry soils). Figure 3 shows plots of $U_{2}^{*} / U_{1}^{*}$ against $\sigma_{2} / \sigma_{1}$ at low $b D_{\mathrm{e}}$ and low decay rate of exudate $(a)$, against $N_{2} / N_{1}$ at low $b D_{\mathrm{e}}$ and high decay rate of exudates $(b)$, and against $\gamma_{2} / \gamma_{1}$ at high $b D_{\mathrm{e}}$ and high and low decay rates $(c)$.
In all cases, all simulated values of $U_{2}^{*} / U_{1}^{*}$ are close to their respective predicted values, and regression lines do not differ from the $1: 1$ line $(P>.05)$. Three maps (maps 2, 4 , and 8; characterized by high $N_{2} / N_{1}$ and $\gamma_{2} / \gamma_{1}$ ) do not fall, however, onto the $1: 1$ line, which is probably because of the low number of roots of one species in maps with high $N_{2} / N_{1}$ (i.e., the chance of bias in the spatial distribution is high in these maps).

\section{Consequences for Nutrient Competition When Only One of the Competing Plants Liberates Exudates}

In the second part of our analysis, we examined the scenario in which the nutrient is available only through the activity of roots $\left(S_{\min }=0\right)$ and when only one species exudes the chemical factor. Figure 4 shows the uptake rate ratios in cases where only species 1 (fig. $4 a$ ) or species 2 (fig. $4 b$ ) exudes the chemical factor. In both cases, species 2 had a maximum sink strength double that of species 1 $\left(\gamma_{2} / \gamma_{1}=2\right)$, but species 2 occupied a smaller soil volume than species $1\left(\sigma_{2} / \sigma_{1}=0.82\right)$. At a low decay rate (squares), the relationship between uptake rate ratio and diffusive supply is identical to the simulated response without exudation (solid line). However, higher values of decay rate slightly change the behavior of the model compared with the situation with constant nutrient supply, particularly at low diffusive supply. Whatever the decay rate, high values of nutrient diffusive supply lead to uptake rate ratios that are similar to cases with constant supply and tend toward the sink strength ratio. However, at low diffusive supply, 

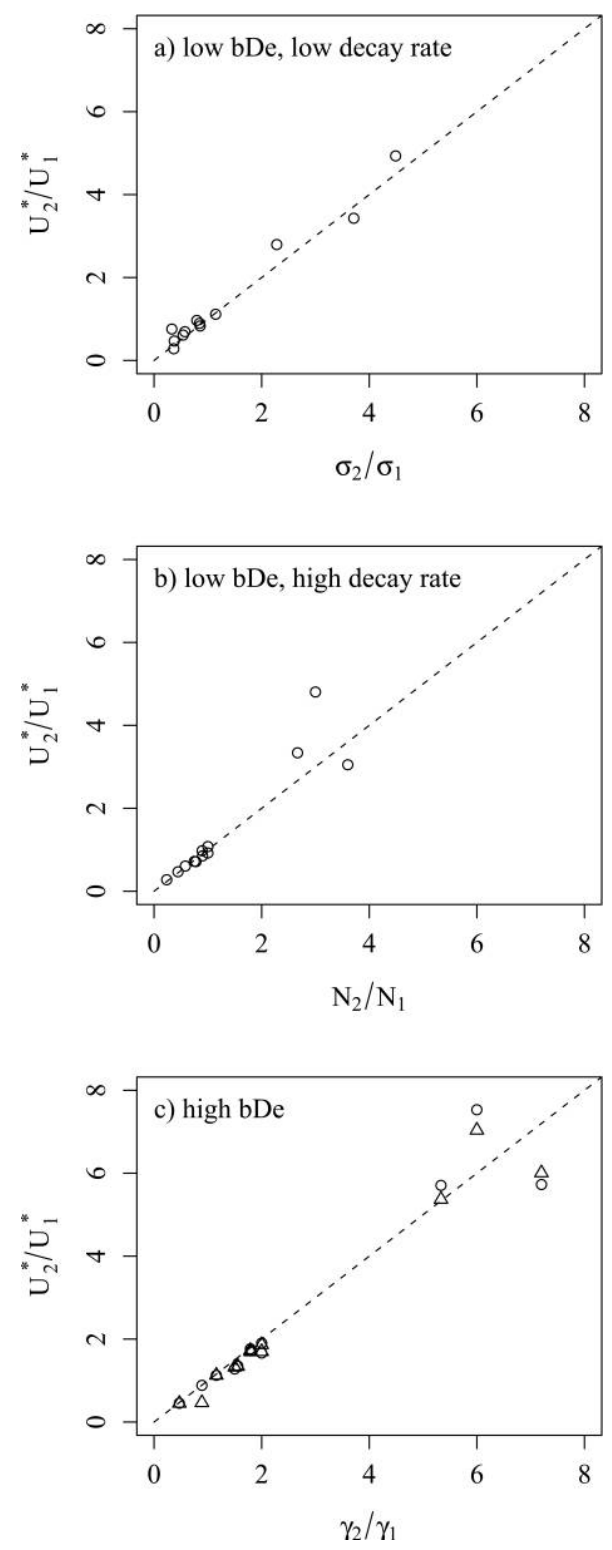

Figure 3: Uptake rate ratio at equilibrium against soil occupation ratio for low $b D_{\mathrm{e}}$ and low decay rate of exudates $(a)$, number of root ratio for low $b D_{\mathrm{e}}$ and high decay rate of exudates $(b)$, and sink strength ratio for high $b D_{\mathrm{e}}$ and low (triangles) or high (circles) decay rate of exudates $(c)$.

the uptake rate ratio is mostly in favor of the species that releases exudates. In theory, if the species altering nutrient supply was the only one able to take it up, uptake rate ratios $U_{2}^{*} / U_{1}^{*}$, as calculated in this study, should be equal to 0 in the case simulated in figure $4 a\left(U_{2}^{*}=0\right)$ and $\infty$ in the case simulated in figure $4 b\left(U_{1}^{*}=0\right)$. Indeed, figure $4 a$ shows that the uptake rate ratio tends toward 0 for low $b D_{\mathrm{e}}$ values, whereas it tends toward infinity in figure $4 b$. Root exudates therefore increase the nutrient uptake of exuding roots in the model within the range of realistic diffusive supplies (i.e., $b D_{\mathrm{e}}$ between $10^{-7}$ and $10^{-5} \mathrm{~cm}^{2}$ $\mathrm{s}^{-1}$ ), especially at the low end of this range, which corresponds to drier soils. This is particularly true when the rate of decay of exudates is high.

Considering that soil availability is not null does not qualitatively change the results when $S_{\min }$ is low compared with $S_{\max }$ (data not shown). However, in the low range of diffusive supply, the species that does not exude the chemical factor can take up some nutrient from soil availability so that the uptake rate ratio $U_{2}^{*} / U_{1}^{*}$ does not tend toward 0 (when species 1 is the exuding species) or $\infty$ (when species 2 is the exuding species) but toward values that depend on the value chosen for $S_{\min }$.

\section{Discussion}

\section{The Extent of the Bioavailability Zone Varies Greatly} with Soil and Root Parameters

Our results show that the soil volume influenced by the roots, that is, the rhizosphere (Hiltner 1904), varies according to numerous parameters. These parameters can be grouped into two major categories: the geometrical parameters, which determine the interception capacity of the whole root system, and the physicochemical parameters, which determine the local acquisition capacity of each root.

The geometrical properties of root systems are mainly root diameter (not studied in this article), root density, and distribution. Both alter the distance between neighboring roots and then the overlap of rhizospheres; the distance between two neighboring roots decreases with increasing density or increasing aggregation of roots. These properties thus determine the nutrient interception by roots and play an important role when taking into consideration root interactions in soil volume.

In contrast, physicochemical parameters of soil and root exudates (e.g., exudation rate, diffusion properties, decay rate) determine the distance to which exudates spread around a single root. These parameters therefore determine the volume where root activity increased bioavailability (the rhizosphere). The higher the exudation rate, the higher the diffusion coefficient, or the lower the decay rate, the greater the distance to which exudates will spread. In cases where a plant must make nutrient available to take it up, the soil volume really exploited by the roots is reduced to the volume determined by the extent of exudates, that is, the rhizosphere. Then the parameters concerning exudates determine the true volume occupied by a plant species $\left(\sigma_{i}\right)$. Few studies have examined the extent of exudate gradients around roots (Wenzel et al. 2001; Chen et al. 2002; Kuzyakov et al. 2003); all have found 

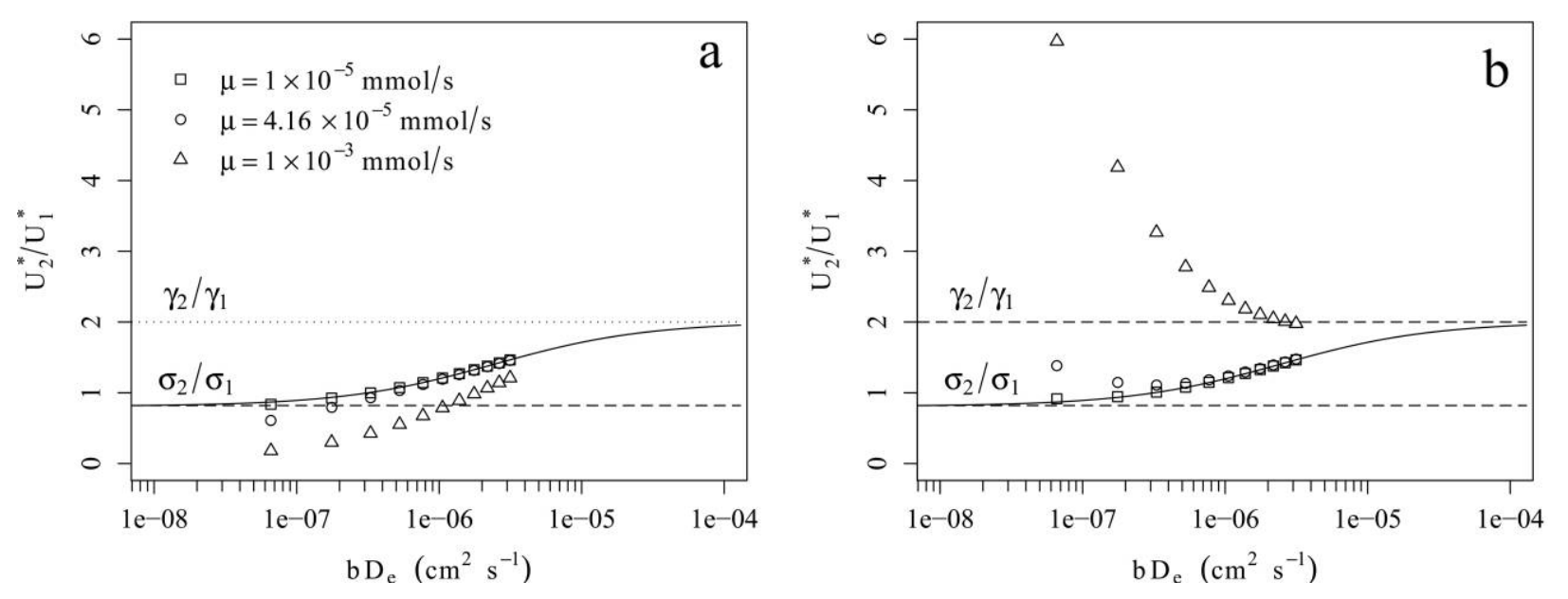

Figure 4: Changes in the uptake rate ratio at equilibrium $U_{2}^{*} / U_{1}^{*}$ as a function of the diffusive supply $b D_{\mathrm{e}}$ when the roots of only one plant species exuded a chemical factor $C$. $a$, Species 1 exuded the chemical factor $C$. $b$, Species 2 exuded the chemical factor $C$. In both cases, species 2 had a maximum uptake rate double that of species $1\left(\gamma_{2} / \gamma_{1}=2\right)$, but species 2 occupied a smaller volume than did species $1\left(\sigma_{2} / \sigma_{1}=0.82\right)$. The bottom horizontal dashed line corresponds to the value of soil occupation ratio $\sigma_{2} / \sigma_{1}$. The top horizontal line corresponds to the value of sink strength ratio $\gamma_{2} / \gamma_{1}$. The chemical factor $C$ was degraded with a decay rate $\mu_{C}$ of $10^{-5}$ (squares), $4.16 \times 10^{-5}$ (circles), and $10^{-3}$ (triangles) $\mathrm{mmol} \mathrm{s}^{-1}$. The sigmoid curve corresponds to the calculated uptake rate ratio under constant nutrient supply.

that the gradients around roots are steep and that exudate concentrations are close to those of bulk soil at ranges of $\sim 2-5 \mathrm{~mm}$ from the root surface. These data suggest that the maximum root densities necessary for "nonoverlapping rhizospheres" are, respectively, $<8$ to 3.5 roots $\mathrm{cm}^{-2}$, assuming that roots grow vertically down into the soil and are regularly distributed. Such densities are low for moderate fertility grasslands but can be common in some poor ecosystems, such as Mediterranean or desert shrublands (Caldwell et al. 1991). These results suggest that neighboring roots should, in general, influence each other's uptake of minerals and that temperate grassland soils are dominated by rhizosphere interactions.

\section{Exudates and Nutrient Partitioning: Importance of the Rhizosphere Overlap}

Experiments have already shown that some plants can render available nutrients to other plants by producing chemicals (Cesco et al. 2006). However, our results suggest that the importance of this phenomenon varies depending on the degree of rhizosphere overlapping between two species. Figure 5 provides a schematic summary of the partitioning of nutrients at low diffusive supply (i.e., low soil water content) between two species for which root exudates increase nutrient availability. Figure $5 a$ shows exudates concentrated around roots because they diffuse slowly and have a high decay rate. In this case, roots take up only nutrients that are made available in their close vicinity, and each species takes up nutrients in proportion to their root density in soil. In this scenario, because the uptake of individual roots does not depend on the presence of other roots, individual roots do not compete for nutrients. Figure $5 c$ shows exudates having a low decay rate so that they spread widely in the soil despite their low diffusive supply. In this case, nutrient supply is maximum throughout the soil, and roots are all in competition for nutrients. The factor that controls the nutrient uptake by a species is then the relative space occupation of its roots, as described in detail by Raynaud and Leadley (2004). Figure $5 b$ shows a situation intermediate between those in $5 a$ and $5 c$. In this case, both root number and space occupation determine nutrient competition, and the degree to which rhizospheres extend beyond the limits of the Thiessen polygons determines which of these two mechanisms dominates. In contrast, at high diffusive supply (high soil water content), nutrient availability is uniform throughout the soil, and uptake rate depends on the relative nutrient uptake capacity of the roots. This is the only case that corresponds to the hypotheses that are the basis of several widely used models of plant competition for nutrients (Tilman 1988; Berendse and Elberse 1990). In systems where rooting density is relatively low and the zone of influence on nutrient availability is limited (which may be the case in arid ecosystems), our model suggests that roots may be more or less independent of each other. In this case, all roots take up nutrients available in their own vicinity, and there is no direct competition between plants for the soil nutrients. 
a

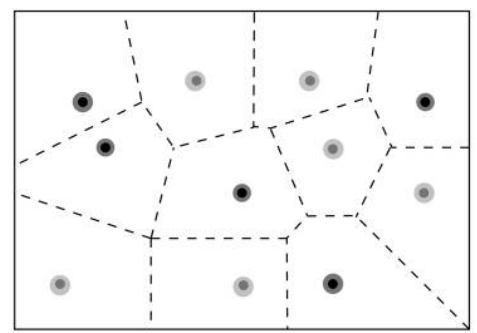

relative uptake $=$ relative root number $U_{2}^{*} / U_{1}^{*}=N_{2} / N_{1}$

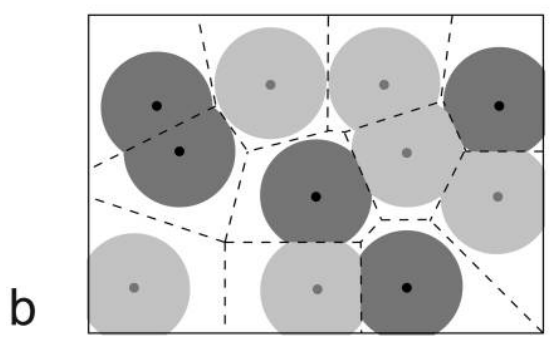

$$
N_{2} / N_{1}<U_{2}^{*} / U_{1}^{*}<\sigma_{2} / \sigma_{1}
$$

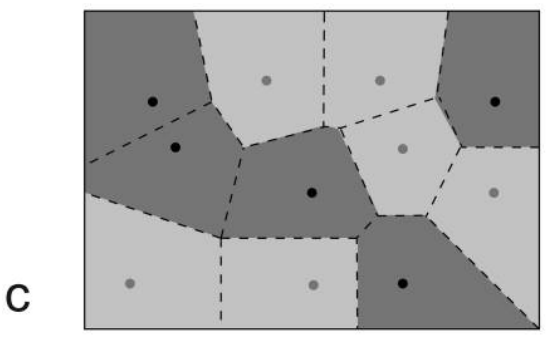

relative uptake $=$ relative space occupation

$$
U_{2}^{*} / U_{1}^{*}=\sigma_{2} / \sigma_{1}
$$

Figure 5: Spreading of the chemical factor $C$ on the nutrient partitioning at low diffusive supply. Light and dark gray correspond to different species. Dashed lines are the Thiessen polygons surrounding each root. $a$, Low spreading, relative uptake rate of a species is equal to its relative number of roots. $b$, Spreading is greater than the smallest Thiessen polygon, relative uptake rate of a species is greater than its relative number of roots but less than its relative occupation of soil. $c$, Spreading is greater than the largest Thiessen polygon, relative uptake rate of a species is equal to its relative occupation of soil.

\section{Generalizing the PARIS-B Results}

The model developed here is not specific of a particular plant, soil, or chemical factor, and our results can be generalized to any other substances that increase bioavailability of nutrient. First, Raynaud and Leadley (2004) have shown using the PARIS-M model that many nutrients may behave similarly to phosphorus in terms of mechanisms regulating competition, because simulated competition was much more sensitive to changes in soil water content than to the type of nutrient. This occurs because diffusion coefficients in pure water of most macronutrients were in the range $0.5 \times 10^{-5}$ to $2 \times 10^{-5} \mathrm{~cm}^{2} \mathrm{~s}^{-1}$ (Vanysek 2000), and thus the range of diffusive supplies of most nutrients is similar (see also Williams and Yanai 1996). Many organic acids have diffusion coefficients in the same range as macronutrients, so their diffusive supply in soil may depend primarily on soil water content (Vanysek 2000). Therefore, most molecules increasing the bioavailability of nutrients through direct, chemical reactions would have a modeled behavior similar to the results we have presented in this article. A remarkable exception is, however, protons that have a very high diffusion coefficient in water $\left(D_{\mathrm{H}^{+}}=\right.$ $9.3 \times 10^{-5} \mathrm{~cm}^{2} \mathrm{~s}^{-1}$ ), which makes their diffusion throughout the soil rapid and should therefore lead, whatever the soil water content is, to patterns of nutrient uptake rate ratios similar to those that we found in our simulations at high soil water content, that is to say, that nutrient availability is high everywhere in the soil. The behavior of molecules increasing nutrient availability through increased turnover rates (such as sugars and the microbial loop) is more difficult to simulate because of the indirect and complex relationship between the release of the molecules by plants and the increase in bioavailability (Bonkowski 2004; Raynaud et al. 2006).

Our simulations are based on the analysis of nutrient uptake by randomly distributed roots. We have not explored the consequences of root aggregation on model output because taking into account root aggregation greatly increases the complexity of model analysis. Observed patterns of root distribution at the scale of individual roots are scarce, but all types of distributions have been observed, from random patterns (Escamilla et al. 1991; van Rees et al. 1994) to regular (van Rees et al. 1994) or clustered distributions (Tardieu 1988; van Rees et al. 1994; Stewart et al. 1999). Using a monospecific model of nutrient uptake by roots, Baldwin et al. (1972) found that nutrient uptake was similar for random and regularly distributed roots, whereas clustered root distributions could reduce the uptake of nutrients because of increased competition between neighboring roots. In our model, the small variations between the calculated uptake rate ratios and their predicted values in our sensitivity analysis (fig. 3) might be due to such interference between roots with short neighboring distances. In addition, interspecific interactions via exudates could be enhanced if interspecific root distances are on average less than those in a random distribution or decreased if the roots of species tend to be isolated from one another. These effects will strongly depend on the ability of solutes to move through the soil (i.e., soil water content) since the zone of influence of a root will increase with increasing soil water content. 


\section{The Effect of Rhizosphere and Plant Species Interactions at the Ecosystem Scale}

Analyzing the behavior of a model of nutrient uptake by competing plants, Craine et al. (2005, p. 933) suggested that "supply preemption, not concentration reduction [was] the mechanism of competition" because the average soil concentration in the absence of competition (i.e., Tilman's $\mathrm{R}^{*}$ ) was not always a good predictor of competitive outcomes in the model. The analysis of the PARIS-M model led Raynaud and Leadley (2004) to similar conclusions, suggesting that the production of a large number of roots is the best competitive strategy at low diffusive supplies because it allows the species with the most roots to exploit the largest volume of soil. Our analysis of the PARIS-B model adds a new dimension to this idea by considering that the plants themselves can increase nutrient availability and that differences in the ability to alter nutrient supply may change the way that we understand competitive interactions. The importance of plant-induced bioavailability can be considered under two different points of view.

The Nutrient Competition Point of View. The simulations presented in figure 4-only one of two species in competition can alter nutrient availability through exudationsuggest that exudation can be advantageous under some conditions but not under others. In particular, at low diffusive supply when the spatial expansion of exudates is limited, increasing the availability of nutrient is highly advantageous for species able to do so, because its own roots recover most of the nutrient. However, at high diffusive supply, the species that do not exude may take up nutrients that are made available through the activity of other species and, therefore, may act as "parasites" of species that have root exudates.

The Ecosystem Engineer Point of View. Because a species that cannot increase nutrient bioavailability may benefit from the presence of species that can, the increase of nutrient bioavailability by some species can also be seen as ecological engineering (Jones et al. 1994). Indeed, the interaction we described above can also be seen as an engineering interaction from the perspective of the species that profits from this bioavailability without generating root exudates. It is also an engineering interaction from an ecosystem perspective, where the presence of exuding species enhances ecosystem function. Such mechanisms have already been described in plant interactions (Cesco et al. 2006). In both situations, the degree to which plants should avoid allowing "parasitism" or being engineers will depend on the costs of exudation, other benefits drawn from exudation, and the profit gained by the other species. The evaluation of the costs of exudation by plants is, however, a difficult task because of the variety of exudates and because some of the exudation mechanisms that can be involved in the alteration of nutrient supply may be seen as by-products of other physiological mechanisms. For example, proton extrusion is a mechanism that is involved in the uptake of cations like ammonium (Haynes 1990; Jaillard et al. 2003), and changes of nutrient availability through proton extrusion can be seen as a by-product of cations uptake. However, proton extrusion is also sometimes a specific response to iron or manganese deficiency (Marschner 1995). Some authors consider that the exudation of organic compounds from root tips is unavoidable (Jones and Darrah 1993). Moreover, the exudation of some complex organic compounds, such as amino acids or other nitrogen-containing molecules, increases the complexity of calculating these costs because plants release nitrogen that may enhance nitrogen availability (Raynaud et al. 2006). In these cases, the cost must be calculated in terms of energy and $\mathrm{N}$ expenditure.

\section{Toward a General Theory of Competitive Interactions for} Nutrients between Plants in Terrestrial Systems

Competition for nutrient resources between plants in terrestrial ecosystems has been a major issue in plant ecology for more than a century. Several authors have tried to understand competitive interactions between plants in terrestrial systems. Two major but opposing theories emerged at the end of the last century (Grime 1979; Tilman 1988), generating a long-lasting debate. Recently, some authors have tried to unify these two theories. Goldberg and Novoplansky (1997) suggested that the existence of temporal variability in resource availability could reconcile both theories. Craine (2005) also provided a general framework to reconcile both approaches of competition, insisting on the idea that nutrient preemption was a major determinant of the outcomes of competition for soil resources. We believe that the modeling architecture provided by PARIS models can help understanding of the mechanisms of competition for nutrient between plants, because the model simulates competition between roots at the spatial scale at which it occurs in nature. Raynaud and Leadley (2004) have already suggested that the Tilman $\mathrm{R}^{*}$ model was valid only for high soil water content because the soil behaved as a well-mixed medium only under these conditions. In contrast, under low soil water content, nutrient diffusion to roots was the factor limiting nutrient uptake, and competing roots do not interact by drawing down bulk soil nutrient concentrations.

Our results with the PARIS-B model emphasize the idea 
that roots could increase nutrient availability by releasing some chemical substances as protons, organic anions, or enzymes and that the outcome of competition may not be adequately predicted by any of the existing theories. At the ecosystem level, nutrient availability would increase as the variety of species with complementary mechanisms of mobilizing nutrients increases (Hauggaard-Nielsen and Jensen 2004). Our analysis also reinforces the idea that the outcomes of competitive interactions depend highly on soil water content and diffusive properties of chemicals in soil. In particular, in highly diffusive media such as wet soils, all roots in a given soil volume can take up nutrient, even those roots that do not modify nutrient availability, and this may occur regardless of the lifetime of the availability factor in the soil. In contrast, in low diffusive media such as dry soils, roots affect only nutrient concentrations in their vicinity, and the lifetime of the availability factor determines whether local nutrient gradients will (longlived molecules) or will not (short-lived molecules) affect the uptake of neighboring roots.

\section{Acknowledgments}

This work was funded by the Université Paris-Sud, the Centre National de la Recherche Scientifique (CNRS), and the program Actions Concertées Incitatives "Ecologie Quantitative" (CNRS/Institut National de la Recherche Agronomique). X.R. would like to thanks C. J. Jones for stimulating discussions concerning some ideas developed in this article. We gratefully thank the associate editor, J. Pastor, and an anonymous reviewer for valuable comments on an earlier version of the manuscript.

\section{APPENDIX A \\ Equations of the PARIS-B Model That Are Shared with PARIS-M}

The model considers a grid of voxels (volume pixels) of root or soil having a hexagonal cross section. The cross section of the hexagons is based on the smallest section of root to be modeled. No flux occurs at the boundary of the voxel grid. This boundary condition corresponds to the assumption that symmetric competition occurs on the other side of the boundary.

\section{Soil-Root Relationships}

If $\Delta x$ is the length of one side of a hexagon, $j$ the index of a soil voxel adjacent to a root $(1 \leq j \leq 6)$, and $C_{j}$ the nutrient concentration in the $j$ th voxel of soil, the equation describing nutrient uptake for root $a$ of the ith species $\left(I_{r, i}\right)$ is (see table 1 for definition of the other parameters)

$$
I_{a, i}=\sum_{j=1}^{6} \Delta x z I_{\max _{i}} \frac{P_{j}}{P_{j}+K_{M}} .
$$

\section{Soil-Soil Relationships}

The diffusive flux, $F_{\mathrm{d}}$, between two adjacent soil voxels is (see table 1 for definition of the other parameters)

$$
F_{\mathrm{d}}=-b D_{\mathrm{e}} \frac{\Delta P}{\Delta x \sqrt{3}} .
$$

\section{APPENDIX B}

\section{Supplementary Tables}

Table B1: Characteristics of root maps used in the sensitivity analysis

\begin{tabular}{lccc}
\hline Map no. & $\begin{array}{c}\text { No. roots ratio } \\
\left(N_{2} / N_{1}\right)\end{array}$ & $\begin{array}{c}\text { Soil occupation ratio } \\
\left(\sigma_{2} / \sigma_{1}\right)\end{array}$ & $\begin{array}{c}\text { Sink strength ratio } \\
\left(\gamma_{2} / \gamma_{1}\right)\end{array}$ \\
\hline 1 & .444 & .376 & .889 \\
2 & 3.6 & 2.281 & 7.2 \\
3 & .894 & .793 & 1.789 \\
4 & 2.667 & 3.711 & 5.333 \\
5 & .9 & .855 & 1.8 \\
6 & .778 & .571 & 1.556 \\
7 & .75 & .331 & 1.5 \\
8 & 3 & 4.488 & 6 \\
9 & .579 & .538 & 1.158 \\
10 & .235 & .365 & .470 \\
\hline
\end{tabular}


Table B2: Nonlinear regression results for data in figure 2

\begin{tabular}{lccc}
\hline Scenarios, $\mu\left(\mathrm{mmol} \mathrm{s}^{-1}\right)$ & $a$ & $i$ & $c$ \\
\hline Map $1:$ & $1.23 \pm 8.13 \times 10^{-3}$ & $2.45 \times 10^{-6} \pm 1.27 \times 10^{-8}$ & $.81 \pm 2.46 \times 10^{-3}$ \\
0 & $1.23 \pm 1.33 \times 10^{-9}$ & $2.45 \times 10^{-6} \pm 1.33 \times 10^{-8}$ & $.81 \pm 2.57 \times 10^{-3}$ \\
$1 \times 10^{-5}$ & $1.18 \pm 2.02 \times 10^{-2}$ & $2.56 \times 10^{-6} \pm 3.15 \times 10^{-8}$ & $.84 \pm 5.88 \times 10^{-3}$ \\
$4.16 \times 10^{-5}$ & $1.20 \pm 2.48 \times 10^{-2}$ & $2.29 \times 10^{-6} \pm 3.81 \times 10^{-8}$ & $.91 \pm 7.20 \times 10^{-3}$ \\
$1 \times 10^{-3}$ & $1.24 \pm 7.74 \times 10^{-3}$ & $1.87 \times 10^{-6} \pm 1.17 \times 10^{-8}$ & $.93 \pm 2.45 \times 10^{-3}$ \\
$1 \times 10^{-2}$ & & & \\
Map $5:$ & $1.03 \pm 1.11 \times 10^{-2}$ & $9.64 \times 10^{-7} \pm 1.37 \times 10^{-8}$ & $1.13 \pm 4.54 \times 10^{-3}$ \\
0 & $1.05 \pm 1.53 \times 10^{-2}$ & $9.33 \times 10^{-7} \pm 1.85 \times 10^{-8}$ & $1.12 \pm 6.38 \times 10^{-3}$ \\
$1 \times 10^{-5}$ & $1.01 \pm 3.00 \times 10^{-3}$ & $9.68 \times 10^{-7} \pm 3.66 \times 10^{-9}$ & $1.11 \pm 1.27 \times 10^{-3}$ \\
$4.16 \times 10^{-5}$ & $1.01 \pm 1.00 \times 10^{-2}$ & $1.23 \times 10^{-6} \pm 1.33 \times 10^{-8}$ & $1.05 \pm 3.94 \times 10^{-3}$ \\
$1 \times 10^{-3}$ & $.98 \pm 1.77 \times 10^{-2}$ & $1.57 \times 10^{-6} \pm 2.5 \times 10^{-8}$ & $1.05 \pm 6.10 \times 10^{-3}$ \\
$1 \times 10^{-2}$ & &
\end{tabular}

Note: Equation is $U_{2} / U_{1}=c+\left(\gamma_{2} / \gamma_{1}-c\right) b D_{\mathrm{e}}^{1 / a} /\left(i^{1 / a}+b D_{\mathrm{e}}^{1 / a}\right)$; see Raynaud and Leadley (2004) for details. All values are significant at the 0.05 level.

\section{Literature Cited}

Baldwin, J. P., P. B. Tinker, and P. H. Nye. 1972. Uptake of solutes by multiple root systems from soil. II. The theoretical effects of rooting density and pattern on uptake of nutrients from soil. Plant and Soil 36:693-708.

Berendse, F., and W. T. Elberse. 1990. Competition and nutrient availability in heathland and grassland ecosystems. Pages 94-116 in J. B. Grace and D. Tilman, eds. Perspectives on plant competition. Academic Press, San Diego, CA.

Bonkowski, M. 2004. Protozoa and plant growth: the microbial loop in soil revisited. New Phytologist 162:617-631.

Calba, H., Firdaus, P. Cazevieille, C. Thé, R. Poss, and B. Jaillard. 2004. The dynamics of protons, aluminium, and calcium in the rhizosphere of maize cultivated in tropical acid soils: experimental study and modelling. Plant and Soil 260:33-46.

Caldwell, M. M., J. H. Manwaring, and S. L. Durham. 1991. The microscale distribution of neighboring plant roots in fertile soil microsites. Functional Ecology 5:765-772.

Cesco, S., A. D. Rombola, M. Tagliavini, Z. Varanini, and R. Pinton. 2006. Phytosiderophores released by graminaceous species promote ${ }^{59} \mathrm{Fe}$-uptake in citrus. Plant and Soil 287:223-233.

Chen, C. R., L. M. Condron, M. R. Davis, and R. R. Sherlock. 2002. Phosphorus dynamics in the rhizosphere of perennial ryegrass (Lolium perenne L.) and radiata pine (Pinus radiata D. Don.). Soil Biology and Biochemistry 34:487-499.

Clarholm, M. 1985a. Interactions of bacteria, protozoa and plants leading to mineralization of soil nitrogen. Soil Biology and Biochemistry 17:181-187.

- $1985 b$. Possible roles for roots, bacteria, protozoa and fungi in supplying nitrogen to plants. Ecological Interactions in Soil 4: 355-365.

- 1989. Effects of plant-bacterial-amoebal interactions on plant uptake of nitrogen under field conditions. Biology and Fertility of Soils 8:373-378.

Craine, J. 2005. Reconciling plant strategy theories of Grime and Tilman. Journal of Ecology 93:1041-1052.

Craine, J. M., J. Fargione, and S. Sugita. 2005. Supply pre-emption, not concentration reduction, is the mechanism of competition for nutrients. New Phytologist 166:933-940.

Dakora, F. D., and D. A. Phillips. 2002. Root exudates as mediators of mineral acquisition in low-nutrient environments. Plant and Soil 245:35-47.

Escamilla, J. A., N. B. Comerford, and D. G. Neary. 1991. Spatial pattern of slash pine roots and its effect on nutrient uptake. Soil Science Society of America Journal 55:1716-1722.

Goldberg, D. E., and A. Novoplansky. 1997. On the relative importance of competition in unproductive environments. Journal of Ecology 85:409-418.

Grime, J. P. 1979. Plant strategies and vegetation processes. Wiley, Chichester.

Hauggaard-Nielsen, H., and E. S. Jensen. 2004. Facilitative root interactions in intercrops. Plant and Soil 274:237-250.

Haynes, R. J. 1990. Active ion uptake and maintenance of cationanion balance: a critical examination of their role in regulating rhizosphere pH. Plant and Soil 126:247-264.

Hiltner, L. 1904. Über neuere Erfahrungen und Probleme auf dem Gebiete der Bodenbakteriologie unter besonderer Berücksichtigung der Gründüngung und Brache. Arbeiten der Deutschen Landwirtschaftlichen Gesellschaft 98:59-78.

Hinsinger, P., O. M. Fernandes Barros, M. F. Benedetti, Y. Noack, and G. Callot. 2001. Plant-induced weathering of a basaltic rock: experimental evidence. Geochimica et Cosmochimica Acta 65:137152

Huston, M. A., and D. L. DeAngelis. 1994. Competition and coexistence: the effect of resource transport and supply rates. American Naturalist 144:954-977.

Ingham, E. R., J. A. Trofymow, R. N. Ames, H. W. Hunt, C. R. Morley, J. C. Moore, and D. C. Coleman. 1986a. Trophic interactions and nitrogen cycling in a semi-arid grassland. I. Seasonal dynamics of the natural populations, their interactions and effects on nitrogen cycling. Journal of Applied Ecology 23:597-614.

. 1986b. Trophic interactions and nitrogen cycling in a semiarid grassland. II. System response to removal of different groups of soil microbes or fauna. Journal of Applied Ecology 23:615-630.

Jaillard, B., C. Plassard, and P. Hinsinger. 2003. Measurements of $\mathrm{H}+$ fluxes and concentrations in the rhizosphere. Pages 231-266 in Z. Rengel, ed. Handbook of soil acidity. Dekker, New York.

Jones, C. G., J. H. Lawton, and M. Shachak. 1994. Organisms as ecosystem engineers. Oikos 69:373-386.

Jones, D. L. 1998. Organic acids in the rhizosphere: a critical review. Plant and Soil 205:25-44.

Jones, D. L., and P. R. Darrah. 1993. Influx and efflux of amino acids 
from Zea mays L. roots and their implications for $\mathrm{N}$ nutrition and the rhizosphere. Plant and Soil 156:87-90.

. 1995. Influx and efflux of organic acids across the soil-root interface of Zea mays L. and its implications in the rhizosphere C flow. Plant and Soil 173:103-109.

Kirk, G. J. D., and M. A. Saleque. 1995. Solubilization of phosphate by rice plants growing in reduced soil: prediction of the amount solubilized and the resultant increase in uptake. European Journal of Soil Science 46:247-255.

Kirk, G. J. D., E. E. Santos, and G. R. Findenegg. 1999a. Phosphate solubilization by organic anion excretion from rice growing in aerobic soil: rates of excretion and decomposition, effects on rhizosphere $\mathrm{pH}$ and effects on phosphate solubility and uptake. New Phytologist 142:185-200.

- 1999b. Phosphate solubilization by organic anion excretion from rice (Oryza sativa L.) growing in aerobic soil. Plant and Soil 211:11-18.

Kuzyakov, Y., A. Raskatov, and M. Kaupenjohann. 2003. Turnover and distribution of root exudates of Zea mays. Plant and Soil 254: 317-327.

Leadley, P. W., J. F. Reynolds, and F. S. Chapin III. 1997. A model of nitrogen uptake by Eriophorum vaginatum roots in the field: ecological implications. Ecological Monographs 67:1-22.

Loosemore, N., A. Straczek, P. Hinsinger, and B. Jaillard. 2004. Zinc mobilization from a contaminated soil by three genotypes of tobacco as affected by soil and rhizosphere pH. Plant and Soil 260: 19-32.

Loreau, M. 1998. Biodiversity and ecosystem functioning: a mechanistic model. Proceedings of the National Academy of Sciences of the USA 95:5632-5636.

Marschner, H. 1995. Mineral nutrition of higher plants. Academic Press, London.

Nielsen, K. L., J. P. Lynch, A. G. Jablokow, and P. S. Curtis. 1994. Carbon cost of root systems: an architectural approach. Plant and Soil 165:161-169.

Olesen, T., P. Moldrup, T. Yamaguchi, and D. E. Rolston. 2001. Constant slope impedance factor model for predicting the solute diffusion coefficient in unsaturated soil. Soil Science 166:89-96.

Paterson, E. 2003. Importance of rhizodeposition in the coupling of plant and microbial productivity. European Journal of Soil Science 54:741-750.
Raynaud, X., and P. W. Leadley. 2004. Soil characteristics play a key role in modeling nutrient competition in plant communities. Ecology 85:2200-2214.

Raynaud, X., J.-C. Lata, and P. W. Leadley. 2006. Soil microbial loop and nutrient uptake by plants: a test using a coupled $\mathrm{C}: \mathrm{N}$ model of plant-microbial interactions. Plant and Soil 287:95-116.

Smethurst, P. J., and N. C. Comerford. 1993. Simulating nutrient uptake by single or competing and contrasting root systems. Soil Science Society of America Journal 57:1361-1367.

Stewart, J. B., C. J. Moran, and J. T. Wood. 1999. Macropore sheath: quantification of plant root and soil macropore association. Plant and Soil 211:59-67.

Tardieu, F. 1988. Analysis of the spatial variability of maize root density. II. Distance between roots. Plant and Soil 107:267-272.

Tilman, D. 1988. Plant strategies and the dynamics and structure of plant communities. Princeton University Press, Princeton, NJ.

Tilman, D., C. L. Lehman, and K. T. Thompson. 1997. Plant diversity and ecosystem productivity: theoretical considerations. Proceedings of the National Academy of Sciences of the USA 94:18571861.

Tinker, P. B., and P. H. Nye. 2000. Solute movement in the rhizosphere. Oxford University Press, Oxford.

van Rees, K. C. J., N. B. Comerford, and P. S. C. Rao. 1990. Defining soil buffer power: implications for ion diffusion and nutrient uptake modeling. Soil Science Society of America Journal 54:15051507.

van Rees, K. C. J., J. A. Hoskins, and W. D. Hoskins. 1994. Analyzing root competition with Dirichlet tesselations for wheat on three landscape positions. Soil Science Society of America Journal 58: 423-432.

Vanysek, P. 2000. Ionic conductivity and diffusion at infinite dilution. Pages 93-95 in D. R. Lide, ed. Handbook of chemistry and physics. CRC, Boca Raton, FL.

Wenzel, W. W., G. Wieshammer, W. J. Fitz, and M. Puschenreiter. 2001. Novel rhizobox design to assess rhizosphere characteristics at high spatial resolution. Plant and Soil 237:37-45.

Williams, M., and R. D. Yanai. 1996. Multi-dimensional sensitivity analysis and ecological implications of a nutrient uptake model. Plant and Soil 180:311-324.

Associate Editor: Claire de Mazancourt Editor: Donald L. DeAngelis 